\title{
Cutaneous leucocytoclastic vasculitis associated with omeprazole
}

\author{
M Odeh, M Lurie, A Oliven
}

Postgrad Med J 2002;78:1 14-1 15

Omeprazole is a potent proton pump inhibitor and usually is well tolerated. Adverse effects of this drug have been reported in up to $5 \%$ of patients, most of which are trivial and disappear rapidly on discontinuation of the drug. Skin adverse reactions attributed to omeprazole are uncommon and include rashes, urticaria, angio-oedema, acute disseminated epidermal necrolysis, lichen spinulosus, and contact dermatitis. Cutaneous leucocytoclastic vasculitis (CLV) has not been previously reported in association with omeprazole. The development of CLV in an elderly patient four weeks after starting treatment with omeprazole is described.

O meprazole is a substituted benzimidazole and a very potent inhibitor of gastric acid secretion due to its inhibiting effect on the parietal cell enzyme $\mathrm{H}^{+} \mathrm{K}^{+}$adenosine triphosphatase. It reduces both basal and stimulated gastric acid secretion, and has been shown to be effective in the treatment of peptic ulcer disease, reflux oesophagitis, and the Zollinger-Ellison syndrome. ${ }^{1}$ In general, omeprazole is well tolerated, and the frequency of its side effects has been similar to that for $\mathrm{H}_{2}$-receptor antagonists. ${ }^{12}$ The majority of reported side effects are only trivial and disappear rapidly on discontinuation of the drug. ${ }^{2}$ Cutaneous adverse reactions attributed to omeprazole are uncommon, with an incidence of $0.5 \%{ }^{2}$ They include rash, contact dermatitis, disseminated epidermal necrolysis, lichen spinulosus, urticaria, and angiooedema. ${ }^{2-6}$ According to data from our drug regulatory agency, the manufacturer, and a Medline search for the last 30 years, cutaneous leucocytoclastic vasculitis (CLV) has not been previously reported in association with this drug.

We describe development of CLV in an elderly patient in association with omeprazole therapy.

\section{CASE REPORT}

A 71 year old woman was admitted with a two day history of palpable skin rash involving both hands and legs and the abdomen, and accompanied with pruritus. She denied fever, any antecedent viral infection, arthritis, respiratory, gastrointestinal, or urinary symptoms.

Four weeks previously she had started treatment with omeprazole, $20 \mathrm{mg}$ daily for epigastric pain, which was considered by her family physician to be due to activation of her old duodenal ulcer. The patient's epigastric pain resolved within a few days after starting treatment with omeprazole and she continued ingestion of this drug. Her other medical history included bronchial asthma treated with a budesonide inhaler for the last few years, and paroxysmal atrial fibrillation treated with amiodarone for the last four months.

Physical examination revealed a normal body temperature and a regular heart rate with 72 beats/min. Heart and lung examination was normal, and no lymphadenopathy, hepatosplenomegaly, or abdominal tenderness were present. Skin

\section{Learning point}

Proton pump inhibitors, particularly omeprazole, are now among the most commonly prescribed drugs worldwide. Omeprazole induced vasculitis is probably rare. However, knowing that systemic vasculitides may also affect visceral organs and can be serious and life threatening, physicians should be aware of the possibility of this adverse reaction, in order to stop treatment with omeprazole early and prevent more serious complications.

examination revealed an erythematous macular, papular rash, 1-10 $\mathrm{mm}$ in diameter over both hands, thighs, and lower abdomen. The buttocks were not involved. Other physical findings were unremarkable.

Laboratory tests revealed the following results: the haemoglobin concentration was $129 \mathrm{~g} / \mathrm{l}$, leucocyte count $7100 \times 10^{9} / 1$ with normal differential count, and platelet count, prothrombin time, and partial thromboplastin time were within normal range. Routine biochemical blood tests were also normal. Serological tests for infection with hepatitis B and C viruses, Epstein-Barr virus, cytomegalovirus, Coxsackie A and B, mycoplasma, and toxoplasma were negative. Antinuclear antibody, rheumatoid factor, and cryoglobulins were also negative. C3, C4, and immunoglobulin levels were normal except IgE which was significantly raised (1560 $\mu \mathrm{g} / \mathrm{l}$, normal $\leqslant 240 \mu \mathrm{g} / \mathrm{l}$ ). Urinalysis was negative for haematuria, proteinuria and granular casts. The chest radiograph was normal.

A skin biopsy was performed, and histopathological studies of the biopsy specimen showed small vessel vasculitis characterised by neutrophilic infiltration, nuclear dust, and focal fibrinoid diposits within the vessels walls (fig lA), up to complete fibrinoid necrosis of the blood vessel, and erythrocyte extravasation in the adjacent dermis (fig $1 \mathrm{~B}$ ).

Treatment with amiodarone and budesonide inhaler was continued, and omeprazole was stopped. Subsequently, the skin lesions completely resolved within a few days without specific treatment. The patient had no further episodes of skin rash over a follow up period of four months; amiodarone and budesonide treatment continued. Rechallenge with omeprazole was not done for ethical reasons.

\section{DISCUSSION}

CLV is an inflammatory vascular disease characterised by prominent involvement of the skin, and by the infiltration of the small blood vessels with polymorphonuclear leucocytes and the presence of leucocytoclasis (fragmentation of nuclei and formation of nuclear dust), and red blood cell extravasation, ${ }^{7}$ as was found in the skin biopsy from our

Abbreviations: CLV, cutaneous leucocytoclastic vasculitis 

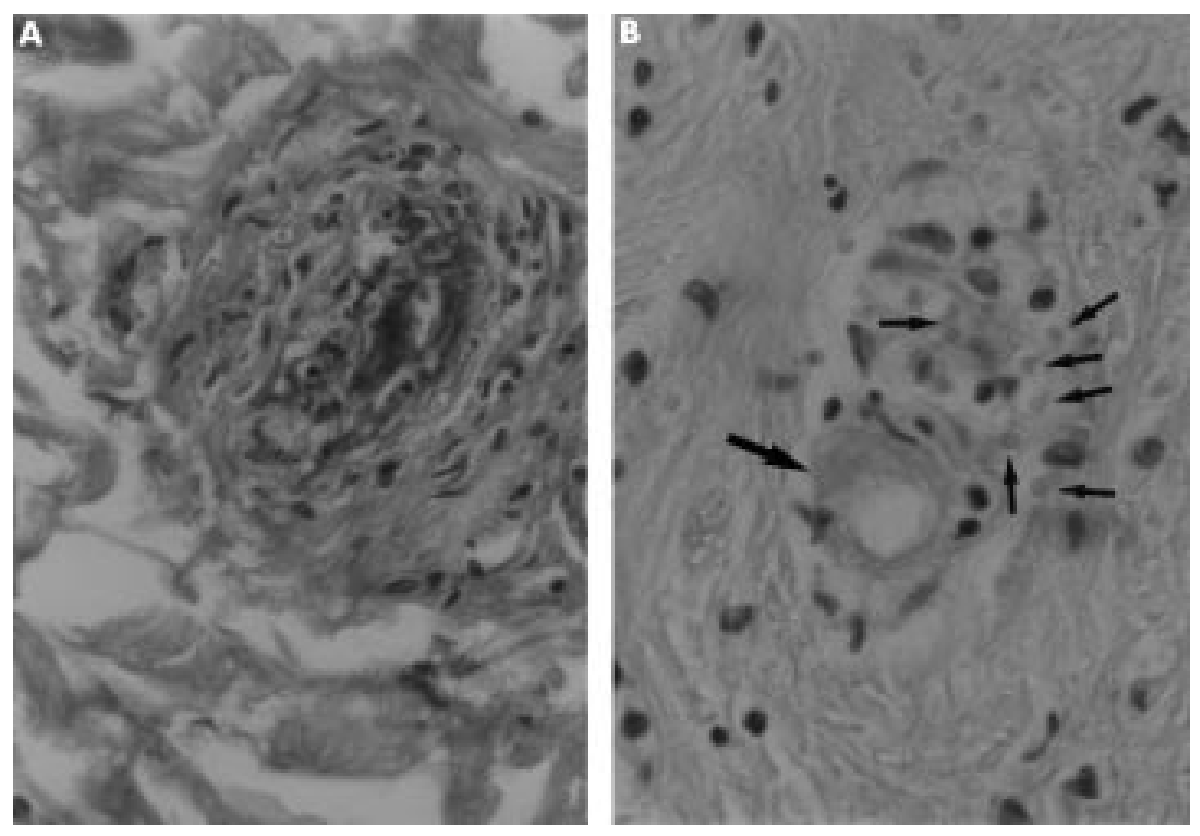

Figure 1 (A) Small dermal blood vessel showing vascular wall damage characterised by neutrophil infiltrate, nuclear dust, and eosinophilic fibrinoid deposits within the vascular wall. (B) Small blood vessel showing complete fibrinoid necrosis (big arrow), and erythrocyte extravasation in the adjacent dermis (small arrows).

patient. This entity can be idiopathic or associated with a variety of underlying conditions including infections, allergic disorders, autoimmune syndromes, or malignant neoplasms. ${ }^{8} \mathrm{~A}$ variety of drugs have been reported to be associated with CLV and include penicillins, sulfonamides and other antibiotics, non-steroidal anti-inflammatory drugs, propylthiouracil, iodides, levamisole, anticonvulsants, and others. ${ }^{9-12} \mathrm{H}_{2}$-receptor antagonists have rarely been associated with hypersensitivity vasculitis, ${ }^{13-15}$ and to the best of our knowledge vasculitis of any type has not previously been reported in association with omeprazole or with any other proton pump inhibitor.

In the absence of any other known cause, development of the skin reaction four weeks after initiation with omeprazole treatment, and rapid reversal of it after withdrawal of the drug, the patient's CLV could be attributed to omeprazole. Cutaneous vasculitis including CLV has been reported, however very rarely, in association with amiodarone. ${ }^{16}{ }^{17}$ Development of the CLV in our patient four months after starting treatment with amiodarone, and its rapid resolution while treatment with amiodarone was continued, suggests that amiodarone is unlikely to be the cause of the CLV.

Omeprazole is usually well tolerated. Adverse effects of this drug have been reported in up to $5 \%$ of patients, most commonly headache, dizziness, diarrhoea, abdominal pain, and fatigue. ${ }^{2}$ There also have been rare reports of skin reactions, hepatic reactions, interstitial nephritis, agranulocytosis, optic neuritis, and anaphylaxis. ${ }^{318}$ Adverse reaction of the skin attributed to omeprazole include rashes, urticaria and angio-oedema, acute disseminated epidermal necrolysis, lichen spinulosus, and contact dermatitis. ${ }^{2-6}$

Proton pump inhibitors, particularly omeprazole, are now among the most commonly prescribed drugs worldwide. ${ }^{18}$ Omeprazole induced vasculitis is probably rare. However, with the understanding that systemic vasculitides may also affect visceral organs and can be life threatening, physicians should be aware of this possibility of adverse reaction of omeprazole in order to stop treatment with the drug early, and to prevent more serious complications.

\section{Authors' affiliations}

M Odeh, A Oliven, Department of Internal Medicine B, Bnai Zion Medical Center, and Technion Faculty of Medicine, Israel Institute of Technology, Haifa, Israel

M Lurie, Department of Pathology, Bnai Zion Medical Center, and Technion Faculty of Medicine, Israel Institute of Technology, Haifa, Israel

Correspondence and requests for reprints to: Dr Majed Odeh, PO Box 6477, Haifa 31063 , Israel

Submitted 31 August 2000

Accepted 15 February 2001

\section{REFERENCES}

1 Maton PN. Omeprazole. N Engl J Med 1991;324:965-75.

2 Nelis GF. Safety profile of omeprazole: adverse events with short-term treatment. Digestion 1989;44(suppl 1):68-76.

3 Ottervanger JP, Phaff RAS, Vermeulen EGJ, et al. Anaphylaxis to omeprazole. J Allergy Clin Immunol 1996;97: 1413-4.

4 Solvell L. Clinical safety of omeprazole. Can J Gastroenterol 1989;3 (suppl A):91A-97A.

5 Meding B. Contact allergy to omeprazole. Contact Dermatitis 1986; 15:36.

6 Haeney MR. Angio-oedema and urticaria associated with omeprazole. BM 1992;305:870.

7 Swerlick RA, Lawley TJ. Cutaneous vasculitis: its relationship to systemic disease. Med Clin North Am 1989;37:1221-35.

8 Gibson LE. Cutaneous vasculitis: approach to diagnosis and systemic association. Mayo Clin Proc 1990;65:221-9.

9 Somer T, Finegold SM. Vasculitides associated with infection, immunization and antimicrobial drugs. Clin Infect Dis 1995 20:1010-36

10 O'Brien WM, Bagby GF. Rare adverse reactions to nonsteroidal antiinflammatory drugs. J Rheumatol 1985; 12:347-53.

11 Verdy M, Pretty $H$, Cadotte $M$, et al. Vasculitis caused by antithyroid drugs. Union Med Can 1975;104:576-9.

12 Roujeau JC, Stern RS. Severe adverse cutaneous reactions to drugs. N Engl J Med 1994;331:2172-85.

13 Michell GG, Magnusson AR, Weiler JM. Cimetidine-induced vasculitis. Am J Med 1983;75:875-6.

14 Andreo JA, Vivancos F, Lopez VM, et al. Vasculitis leukocitoclastica y famotidina. Med Clin (Barc) 1990;95:234-5.

15 Suh J-G, Oleksowicz L, Dutcher JP. Leukocytoclastic vasculitis associated with nizatidine therapy. Am J Med 1997;102:216-7.

16 Staubli $M$, Zimmermann A, Bircher J. Amiodarone-induced vasculitis and polyserositis. Postgrad Med J 1985;61:245-7.

17 Starke ID, Barbatis C. Cutaneous vasculitis associated with amiodarone therapy. BM 1985;291:940.

18 Katelaris PH. Proton pump inhibitors. Med J Aust 1998; 169:208-11. 